\title{
Disputas de significado e identidad: la construcción local del trabajo docente en el contexto de las Políticas de Evaluación e Incentivo al Desempeño en Chile*
}

\author{
Disputes about Meaning and Identity: The Local
}

Construction of Teachers' Work in the Context of Evaluation and Performance Incentive Policies in Chile

Recibido: enero 27 de 2011 | Revisado: febrero 27 de 2012 | Aceptado: marzo 7 de 2012

\author{
VICENTE SISTO ** \\ CARMEN MONTECINOS *** \\ LUIS AHUMADA FigUEROA ***** \\ Pontificia Universidad Católica de Valparaíso, Chile
}

SICI: 1657-9267(201303)12:1<173:DSICLT>2.0.TX;2-3

Para citar este artículo: Sisto, V., Montecinos, C. \& Ahumada, L. (2013). Disputas de significado e identidad: la construcción local del trabajo docente en el contexto de las Políticas de Evaluación e Incentivo al Desempeño en Chile. Universitas Psychologica, 12(1), 173-184.

* Este trabajo tiene el apoyo del Fondo Nacional de Desarrollo de la Ciencia y la Tecnología de Chile (Proyecto FONDECYT № 1090739). Además ha sido patrocinado por el Centro de Investigación Avanzada en Educación (PIA-CONICYT, Proyecto CIE-05).

* Dr. en Psicología Social. Profesor Adjunto e Investigador Asociado del Centro de Investigación Avanzada en Educación. E-mail: vicente.sisto@ ucv.cl

${ }^{* * * *}$ PhD. Profesora Titular e Investigadora Principal del Centro de Investigación Avanzada en Educación. E-mail: carmen.montecinos@ucv.cl

${ }^{* * * * * *}$ Dr. en Psicología. Profesor Titular e Investigador Asociado del Centro de Investigación Avanzada en Educación.E-mail: lahumada@ucv.cl

\section{RESUMEN}

Desde el año 2003, Chile comenzó a implementar una política de evaluación e incentivos con el fin de fortalecer la profesión docente y mejorar la calidad educativa. Mediante un estudio cualitativo de casos, se analizaron los discursos de directores municipales de educación, directores de establecimientos y profesores de dos municipalidades con políticas propias distintas, orientadas al trabajo docente. Los resultados muestran que las distintas políticas implican diferentes significados en torno al trabajo y la identidad docente. Desde la perspectiva de los administradores y directores, las políticas locales son descritas desacreditando la política nacional, pero desde la perspectiva de los profesores, la política nacional se valora positivamente, presentándose como un espacio de aprendizaje colaborativo, marcando la diferencia con las políticas nacionales.

Palabras clave autores

Políticas educativas, nuevo management público, trabajo docente, análisis del

discurso.

Palabras clave descriptores

Educación, identidad docente, pedagogía, Chile.

\section{A B S T R A C T}

In 2003, Chile began to implement a teacher evaluation and incentives policy to strengthen the teaching profession and the quality of education. Using a qualitative case study, we analyzed the discourses of municipal schools administrators, principals and teachers in two municipalities with contrasting local teacher evaluation and incentive policies. The results showed each policy entailed different meanings around teachers work and identity. From the administrators perspective local policies were used to devalue the national policy but from teachers' perspectives, the national policy was used to devalue the local policies.

Key words authors

Educational policy, new public management, teacher's work, discourse analysis.

Key words plus

Education, teaching identity, Pedagogy, Chile. 
Durante los últimos años ha tomado fuerza la idea de que el mejoramiento de calidad de la educación pasa por modernizar su principal fuerza de trabajo: los profesores, considerados como responsables de los resultados de aprendizaje de los alumnos (Vegas, 2008). Es así como se han implementado diversas políticas que buscan aumentar la eficiencia y efectividad del trabajo docente. Sistemas de evaluación del desempeño según estándares, pago dependiente de resultados y diversas formas de contratación flexible emergen como estrategias, promoviendo prototipos de emprendimiento profesional (Gunter, 2008; Maxcy, 2009). Estas transformaciones ocurren en el marco de la paulatina implementación en el sector público de prácticas y modelos de gestión propios de la empresa privada, en lo que se ha llamado Nuevo Management Público (Thomas \& Davies, 2005).

Pero, la puesta en marcha de estas políticas nacionales resulta un proceso complejo. En primer lugar, esta perspectiva prescribe la descentralización. De modo que, junto con el ingreso de proveedores privados que compiten por los recursos del Estado, los de propiedad estatal deben ser administrados por entidades de gobierno local (Wittmann, 2008). Esto tiene como efecto que la política nacional, en su implementación, se encuentre a nivel local con prácticas y políticas propias de los administradores locales (sean públicos, como son las municipalidades en Chile, o privados). A lo anterior se suma que estas políticas, inspiradas en la gestión del sector privado, conllevan modelos de identidad laboral que difieren de aquellas históricamente construidas en el campo del servicio público, ligadas más a la ética de lo público y la transformación social que al incentivo individual ligado a resultados, lo que parece especialmente relevante en el caso de los profesores (Bellei, 2001; Maxcy, 2009; Swann, McIntyre, Pell, Hargreaves \& Cunningham, 2010).

La investigación que aquí se presenta se sitúa en el contexto de la política de evaluación e incentivo al desempeño docente desarrollada en Chile, en tanto una de las principales estrategias nacionales orientadas a fortalecer la profesión (Beca, 2005). A través de un estudio de casos en dos municipios con políticas propias orientadas a la gestión del trabajo docente, se aborda cómo las versiones de trabajo e identidad asociadas a las políticas nacionales de evaluación e incentivo son desplegadas en el contexto de políticas y prácticas locales. Mediante el análisis del discurso de directores municipales de educación, directores de escuelas y profesores, se da cuenta de cómo, desde la posición de estos actores, se construye qué es el trabajo docente y cómo puede ser evaluado e incentivado, mostrando las tensiones y disputas de significado que enmarcan el despliegue de esta política nacional.

\section{La política de evaluación e incentivos al desempeño docente en Chile}

Con la implementación de la Constitución de 1980, y la promulgación de sucesivas leyes, Chile comenzó a desarrollar claramente un modelo de mercado en el campo educativo. Se descentraliza el sistema público al traspasarse la administración de las escuelas a las municipalidades, incorporando prestadores privados de servicios educativos. Todos, establecimientos municipales y privados, compiten por los recursos públicos, en el contexto de un modelo de financiamiento basado en el subsidio a la demanda. La competencia se realiza en el campo de la captación de matrículas y del aseguramiento de la asistencia de quienes están matriculados. La ley prohíbe a la mayor parte de los establecimientos municipales seleccionar estudiantes, de modo que estos reciben a la población más vulnerable. Además, están sujetos al Estatuto Docente que garantiza estabilidad laboral a los profesores. Estas restricciones no se aplican a los privados, sujetos solo a la Ley Laboral nacional, la que les permite una alta flexibilidad en la contratación y desvinculación de profesores, y pueden desarrollar procesos de selección de estudiantes.

En este contexto, son los establecimientos privados los que presentan mejores resultados en el Sistema de Medición de la Calidad de la Educación (SIMCE), que se aplica a 4. y 8.. grado de la Educación Básica y a 2. grado de la Educación Media. Así ha crecido la percepción de que la educación municipal es de baja calidad, coincidiendo con una progresiva pérdida de matrícula en los estableci- 
mientos municipales, en beneficio de los privados (García-Huidobro, 2007).

Entre las diversas políticas desarrolladas para mejorar la educación pública, destacan las orientadas al fortalecimiento de la profesión docente, particularmente la política de evaluación e incentivos al desempeño docente implementada desde el año 2003, fruto de negociaciones entre Gobierno y Colegio de Profesores (organismo que representa a nivel nacional a los docentes). Esta establece criterios para el desarrollo de una carrera ligada a resultados de evaluaciones individuales que miden el cumplimiento de los estándares de desempeño fijados por el Marco de la Buena Enseñanza. Este, según el Ministro de Educación de la época, "establece lo que los docentes chilenos deben conocer, saber hacer y ponderar para determinar cuán bien lo hace cada uno en el aula y en la escuela" (Bitar, 2003, p. 5). De modo que esta evaluación refiere al ajuste del desempeño al estándar y no a los resultados de aprendizaje de los estudiantes. Esta se lleva a cabo mediante una Autoevaluación (cuestionario), Informes de Referencias de Terceros (cuestionarios completados por el director del establecimiento), una Entrevista por un Evaluador Par (otro profesor) y el desarrollo de un Portafolio que exige al docente presentar evidencia que dé cuenta de su mejor práctica pedagógica según una pauta claramente establecida, a lo cual se suma la filmación de una clase.

A partir del análisis de estos datos, se clasifica al profesor en una de las cuatro categorías de desempeño: Insatisfactorio, Básico, Competente y Destacado. Son el portafolio y la filmación las evidencias con mayor peso en este proceso. Los docentes calificados en el nivel Competente o Destacado tienen derecho a rendir voluntariamente una prueba de conocimiento referente al ámbito curricular en el cual ejercen. Si aprueban, obtienen la Asignación Variable por Desempeño Individual (AVDI), que implica un aumento en el salario durante cuatro años. Además, pueden acceder a la Asignación de Excelencia Pedagógica que incluye una nueva prueba escrita y la realización de un nuevo portafolio. Su aprobación les permite acceder a otro incentivo económico de carácter anual durante 10 años, junto con la posibilidad de acreditarse para ingresar a la llamada Red de Maestros de Maestros (RMM). Estos pueden dejar algunas horas de clase para asesorar remuneradamente a otros profesores y escuelas, erigiéndose como un prototipo "de liderazgo en el desarrollo profesional entre pares" (Beca, 2005, p. 9). Los docentes clasificados en el nivel Insatisfactorio deberán evaluarse al año siguiente, ingresando a un Plan de Superación Profesional a cargo, entre otros, de un Maestro de Maestros. Luego de tres malas calificaciones, el profesor deberá dejar la dotación docente.

Tal como se aprecia, la política, a través de sus dispositivos, ofrece un modelo de desempeño que tiene claras consecuencias sobre la identidad profesional. El cumplimiento de estándares, el incentivo económico como movilizador y los prototipos de emprendimiento profesional quedan instalados como referentes para comprender y evaluar al docente. Sin embargo, los sujetos apelados por estas políticas, se desenvuelven en una red de significados construidos localmente "los cuales negocia, revalúa o asume desde su propia historia laboral" (Escobar \& Mantilla, 2007, p. 41). Esta red puede modular y transformar las imágenes de trabajo e identidad docente ofrecidas por la política.

Leicht, Walter, Sainsaulieu y Davies (2009), a través de un estudio en diversos países, mostraron que políticas de profesionalización docente similares generan respuestas muy diversas, según el contexto. Los procesos históricos y sociales nacionales y locales, juegan un rol crítico, lo que toma especial relevancia en el contexto de un sistema descentralizado (Wittmann, 2008). Según Olsen y Sexton (2009), esto es especialmente notorio cuando las identidades profesionales históricamente construidas son desafiadas. De ahí la relevancia de investigar cómo, en el contexto de políticas y prácticas locales, se construyen los modelos de trabajo e identidad docente que trae consigo la política nacional de evaluación e incentivos.

\section{Método}

Dados los objetivos de investigación se ha optado como diseño por un Estudio de Casos de tipo cua- 
litativo, desde la perspectiva discursiva. El Estudio de Casos es una descripción y análisis intensivo de un fenómeno a través de una unidad social, sea un individuo, grupo, institución o comunidad, para lograr descripciones y análisis en profundidad de las relaciones y procesos que constituyen ese fenómeno en su ocurrencia concreta (Merrian, 2002). Su realización bajo una perspectiva discursiva, permite comprender, especialmente en el contexto de organizaciones u otras unidades sociales complejas, cómo son construidos comunalmente los significados, mostrando disputas y tensiones que tienen efectos en la acción social (Phillips \& Hardy, 2002).

\section{Participantes}

Mediante un muestreo intencionado se seleccionaron dos municipios, considerando diferentes tipos de políticas orientadas al desempeño docente y el hecho de contar con estudiantes de un nivel de vulnerabilidad asimilable (las características de cada caso se presentan en la Tabla 1). En cada municipio se realizaron entrevistas semiestructuradas al Director de Educación y al profesional a cargo de la evaluación docente, en el caso que lo hubiera. Además, en cada municipio, fueron entrevistados cuatro directores y seis docentes clasificados en el nivel competente o destacado. Esta muestra se constituyó cuidando la representatividad de la he- terogeneidad estructural que constituye cada caso, siguiendo criterios de muestreo teórico (Glaser \& Strauss, 1967). Así, tanto en el caso de la selección de directores como de docentes, se consideró a hombres y mujeres, de distintos rangos etarios, pertenecientes a establecimientos de educación primaria y secundaria.

\section{Producción de datos}

Los entrevistados aceptaron voluntariamente participar en el estudio, firmando la Carta de Consentimiento Informado, documento revisado y aprobado por el Comité de Ética del Consejo Nacional de Investigación Científica y Tecnológica del Gobierno de Chile. Las entrevistas, de carácter semiestructurado, se guiaron por un protocolo que incluía los siguientes temas: a) iqué es el trabajo docente?; b) icómo este puede ser evaluado e incentivado?; c) valoraciones de las políticas ministeriales y locales de evaluación e incentivos al desempeño docente y d) relaciones entre los diversos agentes (sostenedores, directivos y profesores) en función de la retroalimentación, evaluación e incentivos al desempeño. Cada entrevista duró entre 60 y 95 minutos, y se registró mediante un dispositivo de grabación digital. La transcripción se realizó según el Sistema Jefferson (ver Potter, 1998), el cual permite conservar características del habla relevantes para el análisis.

TABLA 1

Características de los casos estudiados

\begin{tabular}{lcc}
\hline & Municipio 1 & \multicolumn{1}{c}{ Municipio 2 } \\
\hline Tipo de política local & $\begin{array}{l}\text { Alta descentralización en el } \\
\text { control de procesos docentes y } \\
\text { administrativos, con énfasis en los } \\
\text { resultados de aprendizaje. }\end{array}$ & $\begin{array}{l}\text { Control centralizado de procesos } \\
\text { de enseñanza y administrativos. } \\
\text { estándares locales. }\end{array}$ \\
\hline № de profesionales técnico-pedagógicos & 1 & 9 \\
\hline № de Establecimientos & 21 & 12 \\
\hline № de Docentes & 595 & 274 \\
\hline № de Alumnos & 12.872 & 4.734 \\
\hline IVE1 & $65.7 \%$ & $69.7 \%$ \\
\hline
\end{tabular}

Fuente: datos oficiales entregados por cada municipio. 


\section{Análisis de datos}

Siguiendo a Stecher (2010), el análisis del discurso es una herramienta relevante para comprender cómo las nuevas formas de organización laboral se vinculan a las identidades de los trabajadores, generando nuevas formas de acción y relación. Por esto, se realizó un análisis discursivo desde la perspectiva de Potter y Wetherell (1987). Se buscó comprender cómo, en las narraciones y descripciones que realizan los entrevistados, es construido el trabajo docente, cuáles son los criterios que emergen para evaluar e incentivar la acción docente, así como las prescripciones acerca de qué hacer y quiénes deben hacerlo.

\section{Resultados}

El análisis mostró importantes diferencias entre ambos municipios respecto de sus lógicas de gestión y las formas de comprender el trabajo docente, mostrando, en cada uno de ellos, un claro alineamiento entre administración municipal y directores de escuela. Los docentes, en cambio, a pesar de estar sujetos a políticas locales heterogéneas, dan cuenta de una voz común en lo que refiere a cómo debe ser concebido y evaluado el trabajo docente. Es siguiendo esta organización de los datos que se presentan los resultados de la investigación. Para nominar a los diversos hablantes se utilizará la siguiente nomenclatura: E corresponde al entrevistador; $S$ al director de educación, $\mathrm{D}$ a directores y $\mathrm{P}$ a profesores.

\section{Administración municipal y directores del Municipio 1: descentralización y resultados}

El Municipio 1, se caracteriza por un control descentralizado de los procesos. Cada escuela es responsable de la administración de sus recursos humanos, financieros y materiales. El énfasis de la gestión está en los resultados de aprendizaje medidos por pruebas estandarizadas. Por esto, desarrollaron un instrumento de medición de resultados de aprendizaje asimilable al SIMCE pero aplicable a todos los niveles educativos. Esta medición es el principal instrumento de control. Su relevancia, no obstante, trasciende al mero monitoreo, instalán- dose ("la prueba de noviembre"), como el principal referente del trabajo de docentes y directivos. Tal como muestra el siguiente fragmento de la entrevista con el representante de la Dirección Municipal de Educación, es responsabilidad de la dirección municipal solicitar compromisos en torno a metas y otorgar incentivos económicos; los profesores deben cumplir metas, por lo cual son premiados.

S.-(...) dentro del guisado también tenemos contemplados incentivos, incentivos económicos a los que están haciendo bien las tareas, ¿ah? Entonces esto tiene que ver con esto de lo que estoy hablando, compromisos de gestión, usted obtuvo tal y tal resultado, ino cierto? ¿A qué se compromete a tener en la prueba de noviembre que es la última prueba? (...) Lo supervisamos con el director de la escuela, el director debió haberlo conversado con sus profesores y con su equipo técnico y ahí negociamos resultados. E.-Como metas...

S.-Metas, metas, metas, metas, resultados (...) un profesor que está con 44 horas contratadas recibe un buen billete y no solo eso, ese es un bono de rendimiento, hay otros bonos más administrativos.

(Director Municipal de Educación Municipio 1)

El extracto muestra cómo quedan constituidos los diversos sujetos en el relato. El docente emerge como un actor movilizable por incentivos económicos, los que quedan asociados a los resultados en "la prueba de noviembre”. La instalación del nosotros, al señalar "lo supervisamos con el director de la escuela", tiene el efecto de presentar al director como co-responsable del control según resultados de los docentes, junto al sostenedor, poniendo a ambos actores en una misma posición en relación con el profesor y a su acción. La siguiente cita refuerza esta noción de trabajo individual y las posiciones de los actores ahora en relación a los malos resultados.

E.-iY qué pasa con los profesores, por ejemplo, si vemos que hay un curso que está teniendo bajos resultados y eso se empieza a repetir, por ejemplo, en un caso hipotético, qué, qué pasa con eso?

S.-Es el director del colegio el que tiene que resolver el tema, nosotros tenemos, estamos comprometidos 
a no meternos en esa decisión, el director verá, muchos directores de colegio, oye tengo este profesor, resuélvelo tú mismo, ve, ve, mándalo de intercambio de curso y en el peor de los casos empieza a juntar platita y le das una indemnización y lo echas [despides] o busca una fórmula, perdón, un acuerdo. (...) Tus resultados son pésimos, malos y ya le hemos dado 4, 5, 6 oportunidades, en el fondo no te quiero. El director nuestro debiera, debiera entender que tiene que asumir esto y decirle directamente YO NO TE QUIERO EN EL COLEGIO porque tus resultados son estos y ya te hemos dado oportunidades.

(Director Municipal de Educación Municipio 1)

Este extracto muestra dos elementos representativos de este caso. El primero refiere a la descentralización que se traduce en la responsabilización de los directores de establecimiento por resolver los problemas que ocurren en sus establecimientos. Lo problemático queda definido por el alcance de resultados, cuyo logro o fallo en definitiva es responsabilidad del profesor. Sin embargo, es el director el que debe resolver despidiendo al profesor de malos resultados. La preocupación, por lo tanto, no es acerca del desarrollo profesional del docente, sino que de los resultados y de cómo mejorar estos mediante incentivos y castigos individuales. Es significativo que la autonomía del director queda simbolizada en el acto de decirle directamente (al profesor) "YO NOTEQUIERO EN EL COLEGIO". En este contexto las políticas nacionales de evaluación e incentivos son vistas como un obstáculo para los esfuerzos que realiza la dirección municipal.

S.-(...) el sistema nacional nos saca de esa reflexión, porque pone su centro en (e:h) en el profesor.

(Director Municipal de Educación Municipio 1)

Este modo de narrar presenta una oposición entre las preocupaciones de la Dirección Municipal y 'poner el centro en el profesor', lo que tiene que ver con el hecho de que la política nacional se centra en la evaluación de la práctica pedagógica según estándares y no resultados de aprendizaje medidos por las pruebas estandarizadas. El sistema nacional queda así puesto en contradicción con las políticas locales centradas en resultados.
Los directores de establecimientos se alinean ampliamente con esta mirada centrada en resultados, asumiendo el rol de responsables del control.

D.-tú no puedes decir "no es que mira, la Corporación tiene la culpa" iNo! iTú eres responsable! iTú tienes que asumir! ¿Ya? (...) te están colocando acá en el cargo de Directivo para ver si tú tienes logros. (Director/a establecimiento Municipio 1)

El texto muestra no solo el posicionamiento del mismo hablante como responsable por resultados, sino que da cuenta de una teleología que debe guiar el trabajo: los logros. La apelación al entrevistador a través del "tú" permite ampliar la aplicabilidad de la descripción de mundo y de trabajo que está realizando (Potter, 1998). Cada trabajador es responsable y orienta su acción individual en función de logros. En este sentido su trabajo de control se liga a esta relación de premios y castigos a la acción individual en función de los objetivos de logro.

D.-(...) Si tú sabes, si tú tienes buenos resultados, tú te vas a ganar un bono iY te lo van a dar! O sea creo que, bueno, pareciera ser muy pragmático, pero... no, conductista... pero las personas responde-trabajan por estímulos [ríe], ¿no es cierto? (...) Es ( $\uparrow$ mucho) más relevante que a ti, como profesora, te digan "mire profesora, usted se ganó este bono porque usted obtuvo este resultado", ¿me entendí’? a que te digan "el colegio se ganó un bono". Porque iyo soy la profesora de ese curso! Yo soy el profesor de ese curso.

(Director/a establecimiento Municipio 1)

Esta cita marca, además, una distinción entre el reconocimiento individual y el colectivo. Según esta afirmación, es el reconocimiento individual que establece diferencias con los pares, lo que moviliza al individuo.

\section{Administración municipal y directores del Municipio 2: control centralizado para el logro de resultados}

El Municipio 2, se caracteriza por un fuerte control de procesos. En este contexto, la dirección munici- 
pal de educación señala que mejorar los resultados tiene que ver con los procedimientos, planificación y elaboración de clases, lo que permite ciertos resultados de aprendizaje. Por esto se ha orientado al desarrollo de detalladas planificaciones de clases, que los profesores deben ejecutar, siguiendo los estándares diseñados municipalmente. Esto se instala como una responsabilidad de la gestión municipal, lo que se aprecia en la siguiente cita:

S.-La dirección de educación, ha instaurado una línea técnico pedagógica (...), hay coordinadores de lenguaje, coordinadores de matemáticas, coordinadores de ciencias, hay coordinadoras de básica, coordinadoras de media, entonces nosotros como dirección de educación, estamos constantemente acompañando al equipo técnico directivo y a los docentes. Los coordinadores de básica, en párvulo, en lenguaje-matemática van al aula, hacen elaboramiento de clases, elaboran textos de trabajo, elaboran, en conjunto a los docentes, la planificación, se monitorean constantemente a través de instrumentos de medición dentro del área de educación a las escuelas, entonces hay un acompañamiento continuo (...) Primero, constatar que todos los docentes hayan apropiado el marco curricular a la cual enseñan, que tengan claro que-que-tienen que estar enseñando, cómo lo están enseñando, si los chiquillos, cuando entran, cuales son las tareas concretas (...).

(Director Municipal de Educación Municipio 2)

Este tipo de descripciones genera posiciones sociales específicas para los actores. Por una parte, es la dirección municipal la que aparece como protagonista de la acción, ya sea directamente o a través de los coordinadores, quienes elaboran y monitorean. Exceptuando la mención en torno a elaborar "en conjunto a los docentes" la planificación, estos aparecen como entes pasivos, meros ejecutores de lo que ha sido definido por los profesionales de la dirección de educación municipal. Esto se refuerza con la necesidad descrita de constatar que los profesores tengan claridad respecto a tareas básicas de su profesión, como por ejemplo, "qué tienen que estar enseñando”. Así, está claro quiénes saben y quiénes tienen que cumplir. En este contexto, la explicación del éxito en los resultados queda referida a la acción de la dirección municipal, más que a competencias o capacidades de los profesores.

E.-iPor qué cree usted que se da eso (que los docentes han tenido buenos resultados) es algo::, algo circunstancial, o fue algo::?

S.-:no, no creo que haya sido algo circunstancial, yo creo que:: (.) desde la dirección de educación, la directora de educación pre-básica (0.1) ha estado muy:::, muy encima del tema, del trabajo con los docentes.

(Director Municipal de Educación Municipio 2)

La evaluación docente, en este contexto, es descrita como de baja utilidad.

S.-Es un trámite, que es bueno que lo cumplan y también va, a lo mejor, y también se van a ver reflejados en esta evaluación, aunque no sabemos si, el portafolio en si va a reflejar todo lo que él sabe. Porque también sé que colegas mandan a hacer su portafolio.

(Director Municipal de Educación Municipio 2)

Esta cita contiene la utilización de recursos narrativos propios de la retórica irónica descrita por Potter (1998), que tienen el efecto de descalificar a la Evaluación Docente. El primero refiere a su descripción como un trámite, con lo que se socava la valoración del sistema, es algo que hay que cumplir, pero que no sirve. Esto es reforzado con la afirmación "sé que colegas mandan a hacer su portafolio", con lo que se construye al portafolio, principal herramienta de la evaluación docente, como falsificable.

Así como en el Municipio 1, en este caso, también los directores de establecimientos se alinean con el discurso de la Dirección de Educación. Esto se aprecia en el cómo son descritos los docentes, quienes emergen como carentes y desinteresados, poco comprometidos.

D.-(...) yo no digo que sean malos profesores, lo que digo es que están acostumbrados a no hacer las cosas bien, a no cumplir con su pega [trabajo] (...) Si en el sistema municipal no influye, si no ite van a despe- 
dir? tendrías que pegarle a algún alumno, tendría que no sé, hacer acoso a alguna alumna, que te hacen sumario::: tendría que, ese tipo de cosas.

(Director/a establecimiento Municipio 2)

La cita precedente muestra a un profesor acostumbrado a no hacer las cosas bien, a no cumplir con su trabajo. La única posibilidad de movilización es el despido. El profesor queda descrito así como aquel que se mueve en función de evitar el castigo.

Considerando ambos casos, podemos decir que existen importantes diferencias entre ambos en las versiones de trabajo e identidad docente que despliegan. En el Municipio 1, el profesor emerge como un sujeto autónomo orientado a resultados. En el Municipio 2, se trata de un correcto ejecutor de procedimientos, planificaciones y actividades desarrolladas a nivel central. Sin embargo, en ambos casos se mantiene una visión del trabajo docente como una ejecución individual, que debe ser estimulada mediante premios monetarios o castigos individuales. No aparece en las narrativas de directores de establecimientos y administradores municipales la posibilidad de una motivación que apele a la vocación de servicio o al compromiso de los docentes con el bienestar y desarrollo de sus estudiantes. En este marco, el sistema se presenta como un 'trámite', ya que, en el caso del Municipio 1, según los hablantes, evaluaría algo que no tiene impacto en los resultados. En el Municipio 2, no se articula con los objetivos de control de lo que hacen los profesores, descritos como carentes y desinteresados. Es en este marco que los docentes construyen sus propios significados acerca del desempeño docente y de la evaluación docente.

\section{La voz de los profesores}

$\mathrm{Al}$ analizar las entrevistas de los docentes se confirma lo señalado por otras investigaciones en el sentido de que las prácticas y políticas locales parecen fundamentales en el cómo los docentes asumen, valoran y participan de las políticas nacionales (Dall, 2009; Slay \& Smith, 2011). Si bien desde los directivos las políticas locales emergen como mejores alternativas a las políticas naciona- les, la situación contraria se desprende al analizar el discurso de los docentes. En ambos casos, en las 12 entrevistas realizadas a profesores, las nociones de trabajo e identidad docente emergen en disputa a las políticas locales, a través de descripciones que tienden a socavarlas, mostrándolas como limitadas, incapaces de comprender la complejidad de la profesión docente.

En el Municipio 1, la mirada de la Dirección Municipal de Educación (Corporación) se representa como 'estrecha' en cuanto se centra en resultados y no en procesos.

P.-Desde la Corporación Municipal e-es una mirada súper, ehm, estrecha, eh, en el sentido de que el, el, lo que importa son los, lo-los, indicadores externos, pero para llegar a eso nosotros tenemos que, sabemos que, todos tenemos, es como en nuestro inconsciente colectivo sabemos todos que que tenemos que trabajar co-con eh lo primero es trabajar con nuestros alumnos como personas.

(Profesor/a Municipio 1)

Esta cita constituye una oposición entre el énfasis en los indicadores externos y el "trabajar con nuestros alumnos como personas", que es lo que, según esta descripción está "en nuestro inconsciente colectivo" y "sabemos todos". De este modo, el énfasis en indicadores es mostrado como menoscabando lo que se presenta como la 'verdadera naturaleza' de su trabajo. Esta cita muestra otro elemento relevante propio de las entrevistas a los profesores, el uso de la segunda persona plural, el nosotros; la apelación a un 'inconsciente colectivo' o a un conocimiento compartido esboza una mirada del trabajo docente distinta a la individual.

En el Municipio 2 también se socava la visión de trabajo docente adjudicada a la administración municipal, ya que el excesivo control de los procesos, constriñe la enseñanza.

P.-Mandan todo, todo, planificado. Y hay que seguir rigurosamente esa planificación (...) constantemente enviando resultados y haciendo planillas (...) ir clase a clase sin poder salirse un un poquito de sus planificaciones (...) es un proyecto sumamente con- 
ductista o sea tú no te puedes salir y el alumno tiene que escribir con este tipo de letra, en este tipo de cuadrito, y tiene que poner esto en este espacio y tiene que contestar esto para esta pregunta (...) Es decir a los niños los tienes como totalmente cerrados...

(Profesor/a Municipio 2)

La descripción de los procedimientos de control se despliega reforzando la idea de exceso en el control: "todo, todo, planificado". La repetición de la palabra 'todo' da solidez a esta versión de las prácticas y políticas locales, al igual que el uso del "con este tipo de letra, en este tipo de cuadrito". Aquí apreciamos nuevamente el uso de una retórica irónica (Potter, 1998), orientada a socavar la posición opuesta, en este caso, mostrándola como excesiva. La acción del profesor emerge como limitada ("ir clase a clase sin poder salirse un poquito de sus planificaciones”), lo que tendría consecuencias sobre los niños ("los tienes como totalmente cerrados").

Estas descripciones de las políticas locales sirven como telón de fondo en el cual toman forma las valoraciones de la política nacional. Si tanto en el Municipio 1 como en el Municipio 2, los docentes muestran a la política municipal, como una política limitada y limitante, incapaz de abordar la complejidad de su trabajo, el sistema de evaluación docente emerge como un espacio que valora al profesor y a su trabajo. Sin embargo, es importante afinar la mirada hacia qué es lo que permite esta valoración. En ambos casos, a la hora de describir a la Evaluación Docente, los sujetos tienden a mostrarla como un espacio de reflexión y análisis de las propias prácticas, dando especial relevancia a la retroalimentación que realiza un par evaluador en el contexto de la entrevista.

P.-Estuve con mi evaluador par, a propósito de la pregunta, entré en una reflexión que yo no había hecho (...) Lo que yo rescataría de la evaluación docente es, primero que todo, la instancia de evaluación que es para todos. O sea, porque nos da la instancia de reflexión de nuestro quehacer y de volver sistemática cosas que en algún momento fueron una intención, verdad, porqué-e-e que no se vuelva un chiripazo [golpe de suerte] una buena clase, te das cuentaaa [se ríe] o sea en la medida que nosotros volvemos sistemática, podemos entender cómo se están dando nuestras dinámicas, cómo nosotros podamos movilizarnos en la medida que nosotros logramos entender como ocurren estas cosas, y a nosotros mismos.

(Profesor/a Municipio 1)

P.-Por ejemplo esto mismo que te hablaba yo, el desarrollo de habilidades, el conflicto en el aula, la manera que tienes que actuar frente a un alumno (...) Entonces yo creo que la evaluación te sirve para ver qué cosas traes, del conocimiento, del curriculum, de los (lineamiento::s) (curricula::res) y ...eso po.

(Profesor/a Municipio 2)

Tal como se aprecia, las descripciones de la evaluación docente, más que relatar la elaboración del portafolio como un alineamiento de la propia práctica a los estándares nacionales, se centran en dar cuenta de ella como un proceso de análisis reflexivo en torno a la propia práctica, donde el profesor es posicionado como un actor protagónico que es capaz de analizar y dar cuenta de lo que permite una buena práctica. Además, se destaca la instancia de retroalimentación, narrada como una instancia colaborativa que permite sistematizar. Las nociones de retroalimentación, diálogo colaborativo, así como la constitución de sí como sujeto autorreflexivo, emergen con fuerza, como parte constitutiva de las identidades de los docentes. Esto se articula con descripciones que indican que este tipo de trabajo no puede ser comprendido como dependiente de desempeños individuales, cuestionando los incentivos individuales.

P.-Yo no comparto eso [de los incentivos individuales]. Yo creo que es un trabajo de todos, todos eh aportan. Yo ahí no estoy muy de acuerdo, ino? Todo el mundo aportan en el plano de la orientación, hay, hay una serie de cosas (que:) (.) que tienen que ver (...) Es un trabajo de todos, ino?

(Profesor/a Municipio 1)

A través de estas narraciones en torno a la política nacional de Evaluación e Incentivos al Desem- 
peño Docente, los sujetos parecieran desplegar una disputa contra el cómo es significado su trabajo y sus propias identidades laborales por parte de las prácticas y políticas locales. En ambas municipalidades estudiadas, con todas las diferencias que presentan entre sí, estas políticas y prácticas locales son narradas como opuestas a la naturaleza de la profesión docente. En cambio, la evaluación docente, es descrita parcialmente, centrándose solo en ciertos aspectos, mostrándose como articulada con lo que ellos señalan como aspectos propios de la profesión, particularmente la noción del profesor como un sujeto autorreflexivo en el contexto de un trabajo compartido movilizado por su compromiso con los estudiantes, con lo que opone a la comprensión del trabajo docente como un trabajo constitutivamente individual estimulable por incentivos monetarios o castigos.

\section{Discusión y conclusiones}

Las descripciones de las políticas locales y nacionales son construidas con una orientación retórica, reforzando ciertas versiones y atacando alternativas. Esto se aprecia en los recursos, metáforas e imágenes, utilizadas para construir los diversos objetos que emergen en el relato (políticas locales, políticas nacionales, eventos, personas, funciones, etc.). Es en este ejercicio de defensa y ataque que emergen los modelos de identidad laboral que son utilizados como referentes por los sujetos. En el Municipio 1, desde la posición de enunciación de la Dirección Municipal de Educación y de los directores de escuelas, el trabajo docente es constituido como un desempeño individual cuya calidad se define por los resultados en las pruebas estandarizadas. El docente emerge como un sujeto que puede autogestionar su propia acción, orientándola al cumplimiento de metas. La dirección municipal y los directores se posicionan como aquellos que definen las metas, y son responsables de implementar incentivos y castigos que guíen la autogestión del docente. Si bien en el Municipio 2 el trabajo docente también es constituido como un desempeño individual por parte de autoridades municipales y directivos de escuela, este debe ser controlado paso a paso. Los profesores son descritos como carentes y desinteresados, esto justifica el diseño a nivel municipal de lo que debe hacer cada docente. Los buenos resultados, en este caso, son explicables por una buena ejecución a nivel individual de lo planificado centralmente.

Bajo estas políticas locales, en ambos casos, para los administradores, la política nacional de Evaluación Docente parece de poca utilidad. Este es el contexto en el cual los docentes hablan de ella, la que podría ser descrita como una evaluación de desempeños que individualiza el trabajo, o como un llenar formularios (como lo es el portafolio) en función de los objetivos curriculares prescritos y del Marco de la Buena Enseñanza. Sin embargo, en el contexto de esta investigación, se puede apreciar que los docentes, despliegan versiones de la política nacional de evaluación docente que la muestran valorando al profesor como un sujeto que analiza y reflexiona acerca de los procesos de enseñanza y da lugar a lo colaborativo. En efecto, dar cuenta de la política nacional de este modo, tiene la función de dar cuenta del trabajo docente como una actividad de naturaleza distinta a lo que presuponen las políticas locales, según las versiones desplegadas, donde lo que se remarca es el énfasis en resultados.

Según Thomas y Davies (2005), este tipo de disputas en torno a cómo es entendido el trabajo le permiten al sujeto mantener distancia respecto a las adscripciones identitarias que conlleva el Nuevo Management Público, y a la vez lograr sostener las categorías, históricamente constituidas, que aún dan sentido y guían su quehacer (Ranson, 2008), he aquí la función de la versión de la política nacional de evaluación docente, construidas por los docentes, narrada como opuesta a las políticas locales. Siguiendo a Gleeson y Knights (2006), las nuevas políticas de profesionalización orientadas por estándares de desempeño y los modelos de desarrollo profesional individualizante tienden a eclipsar a la ética de lo público como referente identitario. Sin embargo, diversas investigaciones indican que esta ética aún persiste y se muestra de modos heterogéneos, apareciendo como resistencia ante los modelos individualizantes propios del Nuevo Management Público (Gleeson \& Knights, 2006; Grey \& Sturdy, 2010; Gunter, 2008; Maxcy, 2009; Ranson, 2008). 
Según esto, parece necesario profundizar en la investigación de cómo esta ética del servicio público sigue desplegándose a nivel local, mediante qué prácticas y qué procesos colaborativos, así como también de qué modo las nuevas políticas lo están permitiendo y/o dificultando.

\section{Referencias}

Beca, C. (2005). Acciones de desarrollo profesional en Chile: su impacto en las prácticas docentes. Santiago: CPEIP.

Bellei, C. (2001). El Talón de Aquiles de la reforma educativa. En S. Martinic \& M. Pardo (Eds.), Economía política de las reformas educativas en América Latina (pp. 129-146). Santiago: PREAL-CIDE.

Bitar, S. (2003). Presentación del ministro de educación, Sergio Bitar. En MINEDUC (Ed.), Marco de la buena enseñanza. Santiago: MINEDUC.

Dall, H. (2009). New public management, care and struggles about recognition. Critical Social Policy, 29(4), 634-654.

Escobar, H. \& Mantilla, F. (2007). El yo descentrado y situado en la cultura. Universitas Psychologica, 6(1), 39-48.

García-Huidobro, J. E. (2007). Desigualdad educativa y segmentación del sistema escolar. Consideraciones a partir del caso chileno. Pensamiento Educativo, 40(1), 65-86.

Glaser, B. \& Strauss, A. (1967). The discovery of grounded theory: Strategies for qualitative research. New York: Aldine de Gruyter.

Gleeson, D. \& Knights, D. (2006). Challenging dualism: Public professionalism in 'troubled' times. Sociology, 40(2), 277-295.

Grey, Ch. \& Sturdy, A. (2010). A chaos that worked: Organizing Bletchley Park. Public Policy and Administration, 25 (1), 47-66.

Gunter, H. (2008). Policy and workforce reform in England. Educational Management Administration \& Leadership, 36(2), 253-270.

Leicht, K., Walter, T., Sainsaulieu, I. \& Davies, S. (2009). New public management and new professionalism across nations and contexts. Current Sociology, 57(4), 581-605.
Maxcy, B. (2009). New public management and district reform: Managerialism and deflaction of local leadership in a Texas school district. Urban Education, 44(5), 489-521.

Merrian, S. (2002). Qualitative research in practice. San Francisco: Jossey-Bass.

Olsen, B. \& Sexton, D. (2009). Threat rigidity: School reform and how teachers view their work inside current education policy context. American Educational Research Journal, 46(1), 9-44.

Phillips, N. \& Hardy, C. (2002). Discourse analysis: Investigating processes of social construction. Londres: Sage.

Potter, J. (1998). La representación de la realidad. Barcelona: Paidós.

Potter, J. \& Wetherell, M. (1987). Discourse and social psychology. London: Sage.

Ranson, S. (2008). The changing governance of education. Educational Management Administration \& Leadership, 36(2), 201-219.

Slay, H. \& Smith, D. (2010). Professional identity construction: Using narrative to understand the negotiation of professional and stigmatized cultural identities. Human Relations, 64(1), 85-107.

Stecher, A. (2010). El análisis crítico del discurso como herramienta de investigación psicosocial del mundo del trabajo. Discusiones desde América Latina. Universitas Psychologica, 9(1), 93-107.

Swann, M., McIntyre, D., Pell, T., Hargreaves, L. \& Cunningham, M. (2010). Teachers' conceptions of teacher professionalism in England in 2003 and 2006. British Educational Research Journal, 36(4), 549-571.

Thomas, R. \& Davies, A. (2005). Theorizing the micropolitics of resistence: New public management and managerial identities in the UK public services. Organization Studies, 26(5), 683-706.

Vegas, E. (2008). ¿Cómo mejorar las políticas de desarrollo profesional docente a fin de atraer, perfeccionar y retener profesores efectivos? En C. Bellei, D. Contreras \& J. P. Valenzuela (Eds.), La agenda pendiente en educación. Profesores, administradores y recursos: propuestas para la nueva arquitectura de la educación chilena (pp. 48-78). Santiago: Programa de Investigación en Educación Universidad de Chile/UNICEF. 
Vicente Sisto, Carmen Montecinos, Luis Ahumada Figueroa

Wittmann, E. (2008). Align, don't necessarily follow.

Educational Management Administration \& Leadership, 36(1), 33-54. 